\title{
ANALIZA PONAŠANJA ČELIČNOG PRIKLJUČKA STUPA I NOSAČA U VIJČANOJ IZVEDBI PRIMJENOM METODE KOMPONENATA
}

\author{
BEHAVIOR ANALYSIS OF STEEL BEAM-TO- \\ COLUMN BOLTED CONNECTION USING \\ COMPONENT METHOD
}

\author{
Paulina Krolo*, Leona Zajec ${ }^{* *}$
}

\begin{abstract}
Sažetak
U radu je prikazana metoda komponenata za određivanje krutosti i otpornosti na savijanje, što čini osnovne karakteristike priključaka u čeličnim konstrukcijama. Primjena metode komponenata provedena je analitički uz pomoć programa IDEA StatiCa na primjeru priključaka stupa i nosača s obostrano produljenom čeonom pločom u vijčanoj izvedbi. Rezultati dobiveni analitički uspoređeni su s rezultatima numeričkih simulacija dobivenih u programu Abaqus te s rezultatima dobivenim laboratorijskim ispitivanja, a koji su preuzeti iz literature.
\end{abstract}

Ključne riječi: priključak stupa i nosača, metoda komponenata, IDEA StatiCa, HRN EN 1993-1-8

\begin{abstract}
In this paper, the component method for determining the stiffness and bending resistance, which are the basic characteristics of connections, are presented. The application of this method was carried out using the IDEA StatiCa software on the example of the beam-to-column bolted connection with double extended end-plate. The results of the connection behavior were compared to the results obtained by numerical simulation in Abaqus and the results of the behavior obtained by laboratory tests found in references.
\end{abstract}

Keywords: beam-to-column connection, component method, IDEA StatiCa, HRN EN

* Sveučilište u Rijeci, Građevinski fakultet, Radmile Matejčić 3, 51000 Rijeka paulina.krolo@gradri.uniri.hr

** Sveučilište u Rijeci, Građevinski fakultet, Radmile Matejčić 3, 51000 Rijeka lzajec@student.uniri.hr 


\section{Uvod}

Ponašanje priključaka ima značajan utjecaj na ponašanje čeličnih okvira i mora se uzeti u obzir pri globalnom proračunu te pri dimenzioniranju njegovih konstrukcijskih elemenata (stupova i nosača). U konvencionalnoj analizi čeličnih okvira, priključci između stupova i nosača često se pojednostavljuju, tako da ih se razmatra kao zglobne ili krute. Zglobni priključci su oni kod kojih je rotacijska krutost $S_{j}$ idealno jednaka nuli, odnosno, na kraju nosača je omogućena slobodna relativna rotacija $\phi$ te oni kao takvi nemaju nikakvu savojnu otpornost $M_{j . R d}$. Kruti priključci su oni kod kojih se njihova rotacijska krutost $S_{j}$ smatra beskonačnom, tj. nema rotacije $\phi$ između povezanih elemenata te imaju punu savojnu otpornost $M_{j . R d}$. Međutim, ovakvo razmatranje predstavlja idealizirani oblik ponašanja koji ne odražava stvarno ponašanje priključka između stupa i nosača. Ovaj koncept ponašanja konstrukcija istraživali su mnogi autori [1-2].

Stvarno ponašanje priključaka uvijek ima određeni stupanj rotacije $\phi$ i otpornosti na savijanje $M_{j . R d}$ koji je između dvaju spomenutih teoretskih krajnosti, a takve priključke nazivamo djelomično nepopustljivima. Kod djelomično nepopustljivih priključaka, opterećenje kojemu je izložen nosač, prouzročit će moment savijanja $M_{j . E d}$ i odgovarajuću rotaciju priključka $\phi_{E d}$ (Slika 1). Radi određivanja realnog ponašanja priključaka, razvijena je metoda komponenata, koja je uvrštena u europsku normu za projektiranje priključaka HRN EN 1993-1-8 [3].
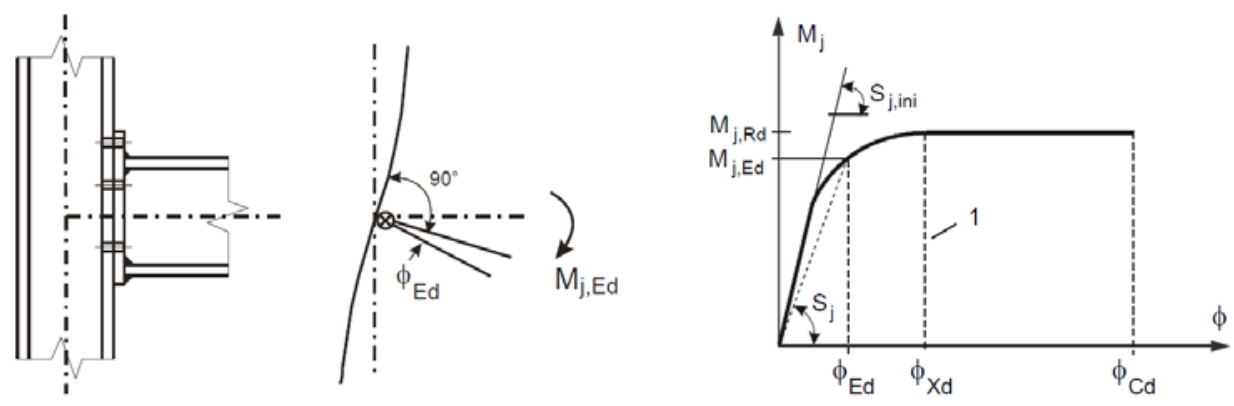

Slika 1. Karakteristična $M-\phi$ krivulja za priključak [3]

Postupak analize djelomično nepopustljivog priključka provodi se na način da se postavi rotacijska opruga u spoju, koja se nalazi u presjeku osi elemenata stupa i nosača. Rotacijska opruga ima tri osnovna svojstva: 
otpornost na savijanje $M_{j . R d}$, rotacijsku krutost $S_{j}$ i rotacijski kapacitet $\phi_{C d}$, koji su prikazani na Slici 1 . Oblik $\mathrm{M}-\phi$ krivulje, odnosno otpornost na savijanje $M_{j . R d}$, rotacijska krutost $S_{j}$ i rotacijski kapacitet $\phi_{C d}$, ovise o svojstvima komponenata (vijci, zavari, ukrute i dr.) od kojih je izveden priključak. $S_{\text {j.ini }}$ je početna rotacijska krutost priključka i predstavlja nagib elastičnog dijela M - $\phi$ krivulje. Rotacijska krutost $S_{j}$ računa se kao sekantna krutost na $\mathrm{M}-\phi$ krivulji, ali ne više od rotacije priključka pri kojoj djelujući računski moment savijanja $M_{j . E d}$ prvi puta doseže proračunsku otpornost $M_{j . R d}$.

U radu je prikazan princip primjene metode komponenata na priključku stupa i nosača u vijčanoj izvedbi s obostrano produljenom čeonom pločom. Cijeli postupak proračuna proveden je u završnom radu koautorice ovoga rada [4]. Budući da je metoda relativno duga i kompleksna, numerički dio proveden je u i programu IDEA StatiCa, koji ima implementiranu samu metodu te su rezultati prikazani u ovom radu. Rezultati dobiveni metodom komponenata uspoređeni su s rezultatima ponašanja dobivenih numeričkim simulacijama koje su proveli Krolo i sur. (2016) [5] te rezultatima laboratorijskih ispitivanja za uzorak SC3 koje su proveli autori Shi i sur. (2010) [6].

\section{Opis vijčanog priključka stupa i nosača}

Metoda komponenata primijenjena je na priključku stupa i nosača s obostrano produljenom čeonom pločom u vijčanoj izvedbi (Slika 2). Podaci o priključcima su preuzeti od Shi i sur. [6], koji su proveli laboratorijska ispitivanja priključaka izloženih monotonom savijanju.

Nosač poprečnog presjeka H-300x200x8x12 je zavaren za čeonu ploču debljine $20 \mathrm{~mm}$ kutnim zavarima s punom penetracijom. Čeona ploča je spojena vijčano za pojasnicu stupa poprečnog presjeka H-300x250x8x12mm s 8 visokovrijednih prednapetih vijaka M20 kvalitete k.v.10.9. Vrijednost sile prednapinjanja u vijcima iznosi $155 \mathrm{kN}$, dobivenih prema kineskoj normi JGJ82-91 (1992). Koeficijent trenja izmjeren na kontaktnim plohama iznosi 0,44 . Dimenzije poprečnih presjeka stupa i nosača dane su u Tablici 1.

Kako bi se spriječilo prijevremeno otkazivanje pojasnice stupa koja je u kontaktu s čeonom pločom, pojasnica stupa je izvedena u jednakoj debljini kao čeona ploča. Pojasnica je podebljana na ukupnoj duljini od $100 \mathrm{~mm}$ ispod i iznad rubova čeone ploče. Stup je ojačan u predjelu hrpta dodavanjem ukruta koje su postavljene u razini osi pojasnica nosača. Debljine limova hrptenih ukruta su $12 \mathrm{~mm}$.

Stup, nosač, čeona ploča i ukrute su izvedeni od čelika Q345. Q 345 je standardna kvaliteta čelika koja se primjenjuje u Kini. Granica popuštanja 
$f_{y}$ te vlačna čvrstoća $f_{u}$ za čelične limove deblje od $16 \mathrm{~mm}$ iznose $363 \mathrm{MPa}$ i $537 \mathrm{MPa}$, dok vrijednost Youngovog modula elastičnosti E iznosi 204227 $\mathrm{MPa}$. Granica popuštanja te vlačna čvrstoća za čelične limove tanje ili jednake $16 \mathrm{~mm}$ iznose $391 \mathrm{MPa}$ i $559 \mathrm{MPa}$, dok vrijednost Youngovog modula iznosi $190707 \mathrm{MPa}$. Vrijednost Poissonovog koeficijenta iznosi 0,3, dok Youngov modul elastičnosti za vijke iznosi $206000 \mathrm{MPa}$.

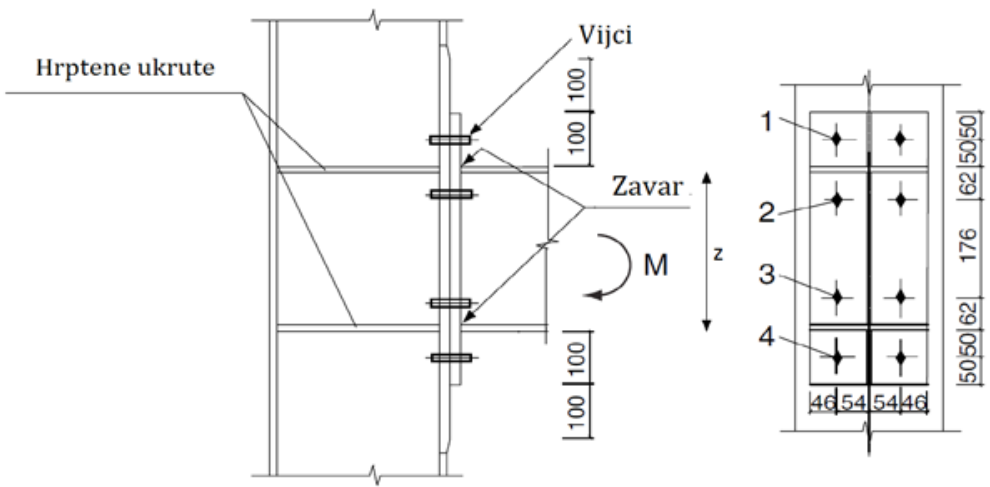

Slika 2. Podaci o priključku [mm] (izradio autor)

Tablica 1. Dimenzije poprečnih presjeka stupa i nosača [mm]

\begin{tabular}{|c|c|c|c|c|}
\hline Element & $\begin{array}{c}\text { Visina } \\
\text { presjeka } \boldsymbol{h}\end{array}$ & $\begin{array}{c}\text { Debljina hrpta } \\
\boldsymbol{t}_{\boldsymbol{w}}\end{array}$ & $\begin{array}{c}\text { Širina } \\
\text { pojasnice } \boldsymbol{b}\end{array}$ & $\begin{array}{c}\text { Debljina } \\
\text { pojasnice } \boldsymbol{t}_{\boldsymbol{f}}\end{array}$ \\
\hline Nosač & 300 & 8 & 200 & 12 \\
\hline Stup & 300 & 8 & 250 & 12 \\
\hline
\end{tabular}

\section{Metoda komponenata}

Metoda komponenata je mehaničko-analitička metoda koja omogućuje karakterizaciju mehaničkog ponašanja priključka. Metodom komponenata se priključak pojednostavljuje mehaničkim modelom koji je sastavljen od opruga i krutih veza. Svaka komponenta priključka predstavlja specifičan dio priključka, pri čemu svaka od njih ima vlastitu otpornost i krutost na vlak, tlak, posmik i/ili savijanje. Da bi se metoda komponenata mogla primijeniti, potrebno je okarakterizirati mehaničko ponašanje svake komponente. Eurocode 3 dio 1-8 [3] razmatra 20 osnovnih komponenti za projektiranje spojeva na čeličnim okvirima. U nastavku je prikazan 
postupak karakterizacije za jednostrani priključak stupa i nosača s obostrano produljenom čeonom pločom u vijčanoj izvedbi.

Na Slici 3 su identificirane komponente priključka, pri čemu su označene komponente izložene djelovanjima tlaka, vlaka, posmika i savijanja. Numeracija pojedinih komponenata odgovara numeraciji prema normi. Komponente pod brojem 6 i 9 nisu karakteristične za ovaj tip priključka.

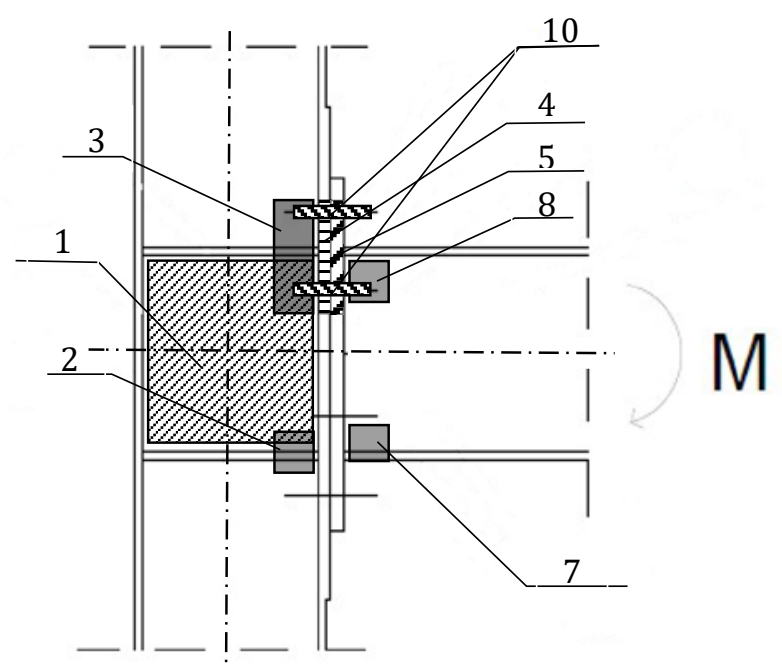

1 - Hrbat stupa opterećen na posmik

2 - Hrbat stupa opterećen na tlak

3 - Hrbat stupa opterećen na vlak

4 - Pojasnica stupa opterećena na savijanje

5 - Čeona ploča opterećena na savijanje

7 - Hrbat i pojasnica nosača opterećeni na tlak

8 - Hrbat nosača opterećen na vlak

10 - vijak opterećen na vlak

Slika 3. Komponente priključka stupa i nosača s obostrano produljenom čeonom pločom (izradio autor)

\subsection{Rotacijska krutost priključka}

Početna rotacijska krutost priključka $S_{j . i n i}$ određuje se na temelju krutosti osnovnih komponenata:

$$
S_{j . i n i}=\frac{E \cdot z^{2}}{\mu \cdot \sum_{i} \frac{1}{\bar{k}_{i}}}
$$


U izrazu (1) $E$ je modul elastičnosti čelika, $z$ je udaljenost od središta tlaka koji pada u težište pojasnice do točke koja pada u težište između dvaju redova vlačnih vijaka, $S_{j . i n i} / S_{j}$ je omjer krutosti $k_{i}$, dok je krutost pojedine komponente priključka koje su prikazane na Slici 2. Za jednostrane priključke $s$ dva ili više redova vlačnih vijaka, za proračun krutosti priključka potrebno je uzeti u obzir krutosti komponenata $k_{1}$ i $k_{2}$ te ekvivalentu krutost $k_{e q}$ za dva reda vijaka. Rotacijska krutost priključka dobiva se iz kombinacije krutosti komponenata, a slijed izračunavanja krutosti prikazan je na Slici 4 i definiran u Eurocodeu 3 [3].

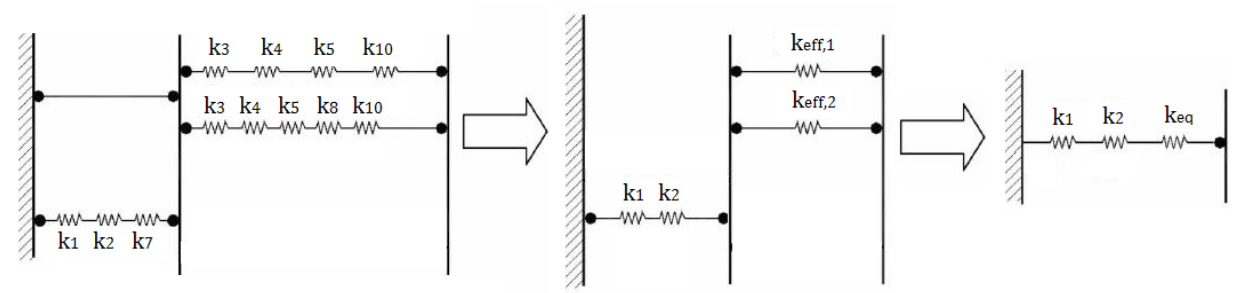

Slika 4. Mehanički model priključka s oprugama (izradio autor)

Prema izrazu (1), rotacijska krutost navedenog tipa priključka računa se kao:

$$
S_{j . i n i}=\frac{E \cdot z^{2}}{\mu \cdot\left(\frac{1}{k_{1}}+\frac{1}{k_{2}}+\frac{1}{k_{e q}}\right)}
$$

Ekvivalentni koeficijent krutost dobiva se prema izrazu:

$$
k_{e q}=\frac{\sum_{r} k_{e f f, r} h_{r}}{z_{e q}}
$$

U izrazu (3), predstavlja udaljenost između vijaka u redu $r$ i centra tlaka, $k_{e f f, r}$ je efektivni koeficijent krutosti za vijke u retku r, uzimajući u obzir krutosti svih komponenata priključka u razini vijaka u retku r, a $z_{e q}$ predstavlja ekvivalentni krak, prikazan na Slici 7.

Efektivni koeficijent krutosti za vijke u retku r se računa prema izrazu:

$$
k_{e f f, r}=\frac{1}{\sum_{i} \frac{1}{k_{i, r}}}
$$

U izrazu (4) $k_{i, r}$ je koeficijent krutosti komponente priključka u razini vijka u retku r. Ekvivalentni krak treba odrediti prema izrazu:

$$
z_{e q}=\frac{\sum_{r} k_{e f f, r} h_{r}^{2}}{\sum_{r} k_{e f f, r} h_{r}}
$$


Za priključke stupa i nosača $s$ čeonim pločama, pri proračunu efektivnog koeficijenta krutosti (4), krutosti komponenti $k_{i, r}$ koje treba uzeti u obzir su: hrbat stupa opterećen na vlak $k_{3}$, pojasnica stupa opterećena na savijanje $k_{4}$, čeona ploču opterećenu na savijanje $k_{5}$ i vijak opterećen na vlak $k_{10}$ Koeficijenti krutosti $k_{i}$ definirani su u [3], a potrebno ih je izračunati u razini vijka u retku $r$ za dva reda vijaka.

Prema početnoj rotacijskoj krutosti, priključci se mogu razvrstati u tri područja [3] (Slika 5). Prvo područje se odnosi na krute priključke, a kriteriji se razlikuju ovisno o tipu okvira, odnosno je li okvir poduprt ili nepoduprt. Treće područje zauzimaju zglobni priključi, dok se između prvog i trećeg područja nalaze djelomično nepopustljivi priključci. Klasifikacija priključaka na krute, djelomično nepopustljive ili zglobne priključke provodi se tako da se napravi usporedba računske krutosti priključka s graničnim krutostima.

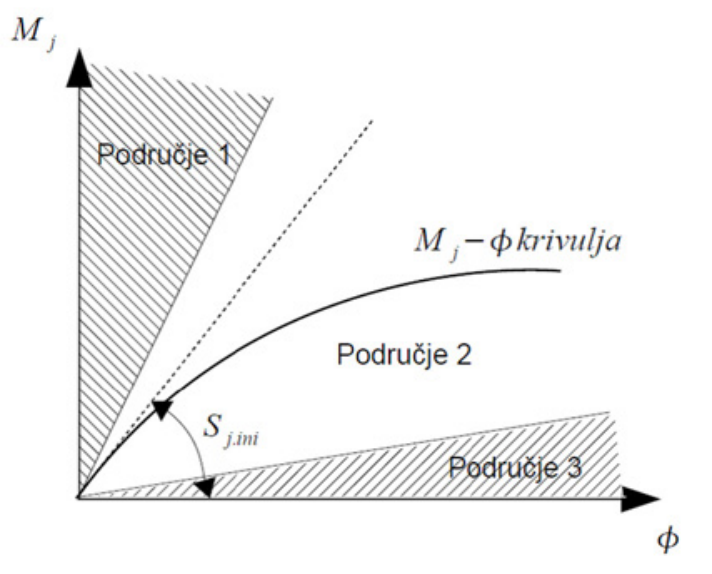

$\boldsymbol{S}_{j . i n i}$ - početna rotacijska krutost priključka; $\boldsymbol{E}$ - modul elastičnosti čelika;

$\boldsymbol{I}_{\boldsymbol{b}}$ - moment tromosti grede; $\boldsymbol{L}_{\boldsymbol{b}}$ - raspon grede (od osi do osi stupova)

Slika 5. Razredba priključaka prema rotacijskoj krutosti (izradio autor)

\subsection{Proračunska otpornost priključka na savijanje}

Proračunsko djelovanje momenta savijanja $M_{j . E d}$ treba zadovoljiti uvjet:

$$
\frac{M_{j, E d}}{M_{j, R d}} \leq 1
$$

Proračunska otpornost na savijanje može se odrediti iz izraza:

$$
M_{j, R d}=\sum h_{r} \cdot F_{t r, R d}
$$


U izrazu (7), $F_{t r, R d}$ je efektivna proračunska vlačna otpornost vijaka u retku $\mathrm{r}, h_{r}$ je udaljenost reda vijaka od središta tlaka, a r predstavlja broj retka vijka. U vijčanim spojevima s više od jednog reda vlačno opterećenih vijaka, prvi red vijaka predstavlja najudaljeniji red od centra tlaka. Centar tlaka se uzima kao linija koja pada u težište tlačne pojasnice. Vlačna otpornost pojedine komponente spoja računa se u razini svakog reda vlačnog vijka. Efektivna proračunska vlačna otpornost vijaka $u$ redu $r$ bit će jednaka najmanjoj vrijednosti vlačne otpornosti pojedine komponente spoja u razini tog reda vijaka. Konkretno, za primjer priključka s dva reda vlačnih vijaka vrijedi:

$$
F_{t r, R d}=\min \left(F_{t, w c, R d} ; F_{t, f c, R d} ; F_{t, e p, R d} ; F_{t, f w b, R d}\right)
$$

U izrazu (8), $F_{t, w c, R d} F_{t, f c, R d} F_{t, e p, R d} F_{t, f w b, R d}$ redom označavaju proračunsku vlačnu otpornost hrpta stupa (wc - column web), proračunsku vlačnu otpornost pojasnice stupa (fc - column flange), proračunsku vlačnu otpornost čeone ploče (ep - end-plate) i proračunsku vlačnu otpornost hrpta nosača (wb - beam web). Formulacije za proračune vlačnih otpornosti dane su u [3].

\section{Usporedba rezultata}

U nastavku su dani rezultati proračuna priključka primjenom prethodno opisane metode komponenata. Metoda je implementirana u programskom paketu IDEA StatiCa, u kojemu je izrađen mehanički model priključka prikazan na Slici 6.

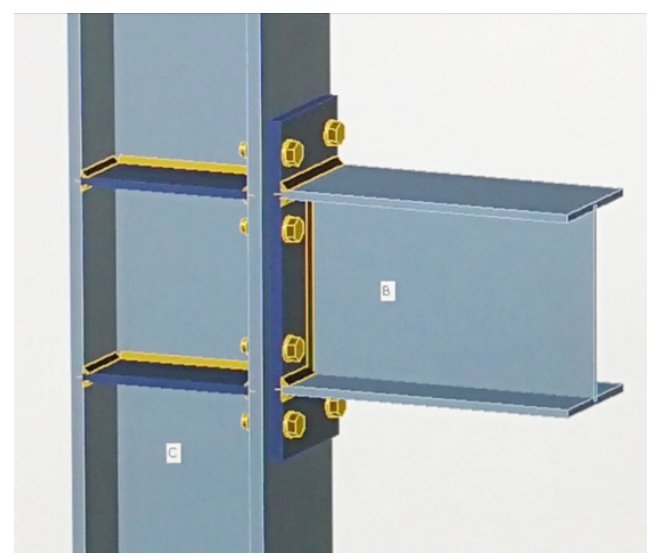

Slika 6. Model priključka izrađen u IDEA StatiCa programu

Kao rezultat proračuna priključka, određene su krivulje odnosa momenta savijanja M i rotacije $\phi$, koji omogućuje prikaz ponašanja priključka na utjecaj monotonog savijanja. Ukupna rotacija priključka $\phi$ je jednaka sumi 
rotacije pojasnice stupa $\phi_{\mathrm{c}}$ i rotaciji čeone ploče $\phi_{\mathrm{ep}}$ (Slika 7). Rotacija stupa $\phi_{c}$ nastaje uslijed posmičnih deformacija koje se javljaju u panelu hrpta stupa i deformacija ostalih komponenata stupa. Rotacija čeone ploče $\phi_{\text {ep }}$ nastaje uslijed deformacija gornje i donje pojasnice zbog djelovanja vlaka i tlaka te deformacija čeone ploče uslijed djelovanja savijanja.

$M-\phi$ dijagrami dobiveni metodom komponenata prikazani su na Slici 8, zajedno s $M-\phi$ dijagramima koji su dobiveni numeričkim simulacijama koje su proveli Krolo i sur. [5] te laboratorijskim ispitivanjima uzorka SC3 koje su proveli Shi i sur. prema [6].

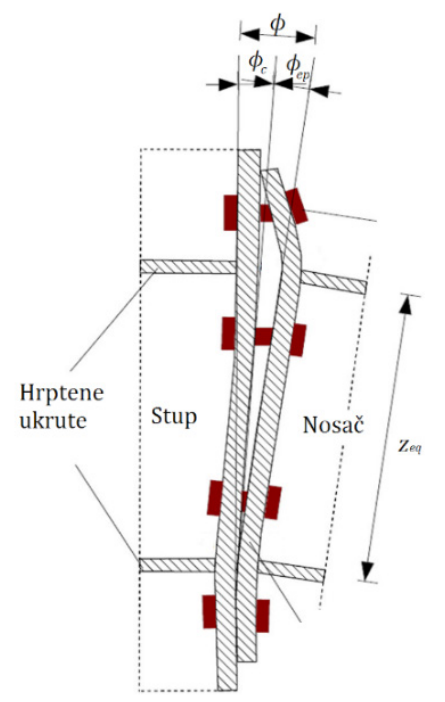

Slika 7. Rotacija spoja

Početna rotacijska krutost priključka $S_{j . i n i}$ izračunata je prema formulacijama navedenim u ovom radu, dok je na $M-\phi$ dijagramima, koji su dobiveni numeričkim simulacijama te laboratorijskim ispitivanjima, početna rotacijska krutost $S_{j . i n i}$ definirana kao nagib sekante te predstavlja sekantnu rotacijsku krutost priključka. Dobivene rotacijske krutosti $S_{j . i n i}$ te vrijednosti proračunske otpornost na savijanje $M_{j . R d}$ dane su u Tablici 2.

Tablica 2. Prikaz rezultata

\begin{tabular}{|c|c|c|c|}
\hline & $\begin{array}{c}\text { Metoda } \\
\text { komponenata }\end{array}$ & $\begin{array}{c}\text { FEM prema } \\
\text { Krolo i sur. [5] }\end{array}$ & $\begin{array}{c}\text { Test prema Shi } \\
\text { i sur. [6] }\end{array}$ \\
\hline $\boldsymbol{S}_{\boldsymbol{j} \boldsymbol{. \boldsymbol { n } \boldsymbol { i }}[\mathrm{kNm} / \mathrm{rad}]}$ & 45466 & 50348 & 51553 \\
\hline $\boldsymbol{M}_{\boldsymbol{j} \boldsymbol{R \boldsymbol { d }}}[\mathrm{kNm}]$ & 245,7 & 308,28 & 308,3 \\
\hline
\end{tabular}


Iz rezultata prikazanih u Tablici 2 može se vidjeti da se početna rotacijska krutost priključka $S_{j . i n i}$ dobivena metodom komponenata razlikuje za $11 \%$ i $13 \%$ u odnosu na rezultate dobivene numeričkim simulacijama i laboratorijskim ispitivanjima.

a)

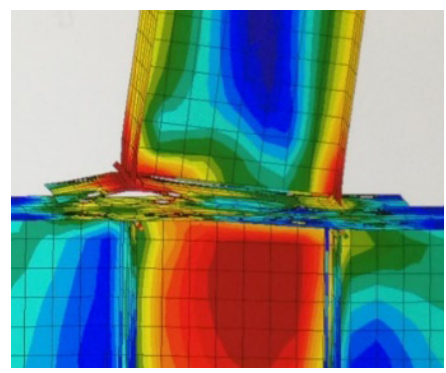

b)

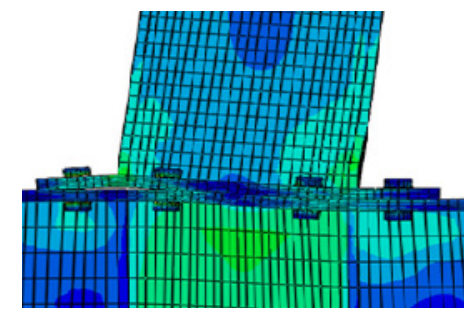

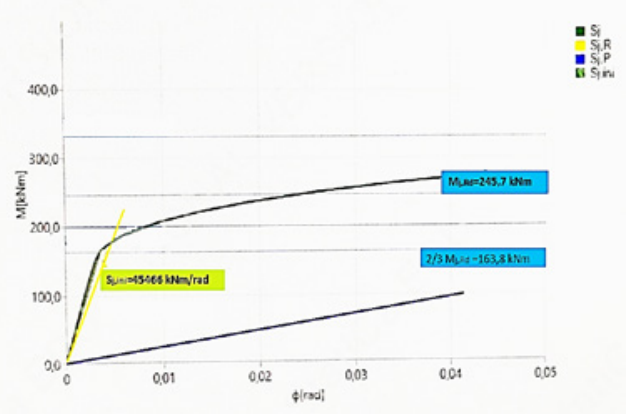
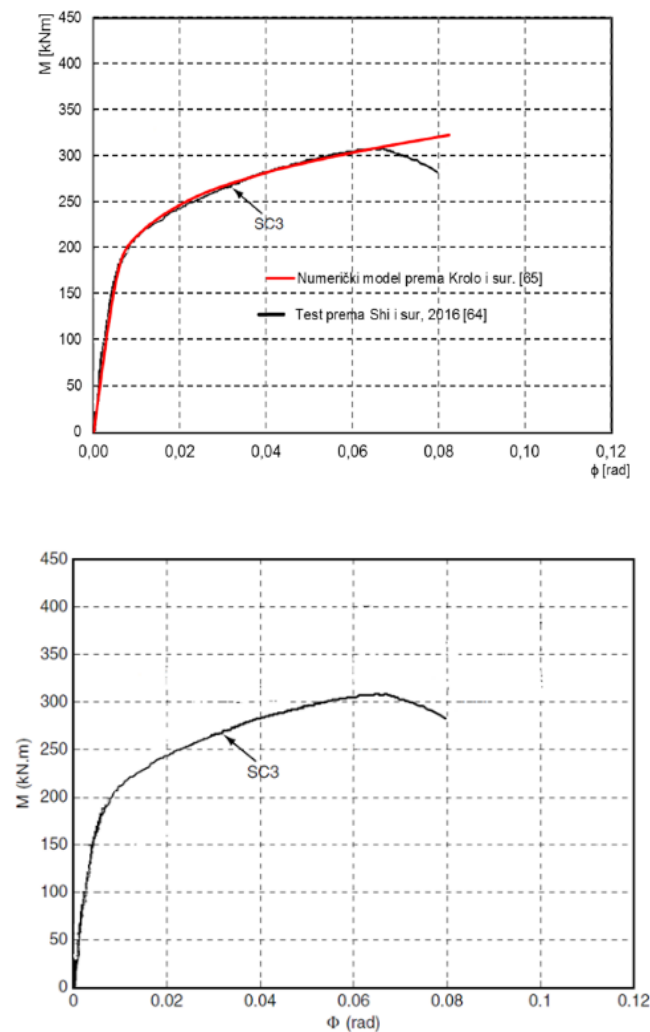

c)

Slika 8. Oblici otkazivanja priključaka (lijevo) te $M-\phi$ dijagrami (desno) dobiveni a) metodom komponenata, b) numeričkim simulacijama prema Krolo i sur. [5] i laboratorijskim ispitivanjima prema Shi i sur. [6] 
Prema početnoj rotacijskoj krutosti, priključak je klasificiran kao kruti, što je vidljivo i na dijagramu a) Slika 8. Crvena linija definira granicu Područja 1, kojemu pripadaju kruti priključci, dok plava linija definira granicu Područja 3, kojemu pripadaju zglobni priključci. Razradba priključaka prema rotacijskoj krutosti prethodno je pojašnjena na Slici 5.

Otpornost priključka na savijanje $M_{j . R d}$ dobivena metodom komponenata razlikuje se za $25 \%$ u odnosu na rezultate dobivene numeričkim simulacijama i eksperimentalno. Metoda komponenata uzima u obzir parcijalni koeficijent sigurnosti koji iznosi 1,25, što zasigurno utječe na razliku u rezultatima s numeričkim simulacijama i eksperimentalnim rezultatima. Osim toga, uočeno je da su vrijednosti sila prednaprezanja vijaka tijekom laboratorijskim ispitivanja bile znatno veće od propisane proračunske vrijednosti, koja po kineskoj normi iznosi $155 \mathrm{kN}$. Izmjerene vrijednosti sila prednaprezanja iznose $185 \mathrm{kN}$, što zasigurno utječe na vlačnu otpornost vijaka, ali i na otpornost cijelog priključka.

Oblik otkazivanja priključaka dobiven metodom komponenata odgovara oblicima otkazivanja koji su dobiveni numeričkim simulacijama i eksperimentalno. Oblik sloma laboratorijskog modela priključka može se vidjeti u radu autora Shi i sur. [6]. Otkazivanje kod sva tri model nastupa prekoračenjem vlačne otpornosti gornjeg reda vijaka.

\section{Zaključak}

U radu je predstavljena metodologija proračuna priključaka primjenom metode komponenata. Metoda je primijenjena na priključak stupa i nosača s obostrano produljenom čeonom pločom u vijčanoj izvedbi uz pomoć programa IDEA StatiCa. Određeni su dijagrami odnosa momenata savijanja $M$ i rotacije priključka $\phi$ koji opisuju ponašanje priključaka pri monotonom savijanju. Osim toga, određena je početna rotacijska krutost priključka otpornost priključka na savijanje te prikazani modeli priključaka s oblicima otkazivanja. Rezultati dobiveni metodom komponenata su uspoređeni s rezultatima dobivenim numeričkim simulacijama iz [5] te rezultatima laboratorijskih ispitivanja iz [6].

Početna rotacijska krutost $S_{j . i n i}$ dobivena metodom komponenata daje zadovoljavajuće rezultate u odnosu na krutosti dobivene numeričkim simulacijama i laboratorijskim ispitivanjima. Otpornost priključka na savijanje $M_{j . R d}$ dobiven metodom komponenata znatno se razlikuje u odnosu na rezultate numeričkih simulacija i laboratorijskih ispitivanja. Moguće je da na rezultate utječe razlika u odabranim vrijednostima sila prednaprezanja vijaka, koje su primijenjene u mehaničkom modelu kod metode komponenata te u numeričkom i laboratorijskom modelu. 
Metoda komponenata je pogodna za karakterizaciju ponašanja priključaka, odnosno za pronalaženje njegove krutosti i otpornosti. Poznavanjem ovih parametara moguće je odrediti je li priključak zglobni, kruti ili djelomično nepopustljiv. Uvažavanjem stvarnog ponašanja priključaka tijekom proračuna čeličnih okvira znatno se utječe na raspodjelu unutarnjih sila, momenata savijanja i pomaka u konstrukciji, što dovodi i do ekonomičnijih rješenja same konstrukcije.

Zahvala. Rad je nastao kao rezultat istraživanja u okviru projekta „Poboljšanje proračunskih modela za ocjenu stanja građevinskih konstrukcija", uniri-tehnic-18-127, koje financira Sveučilište u Rijeci.

\section{Literatura}

[1] Faella, C., Piluso, V. i Rizzano, G. (2000) Structural Steel Semi-Rigid Connection: Theory, Design and Software, Boca Raton: CRC Press

[2] Jaspart, J. P. (2000) General Report: Session on Connection, Journal of Constructiona Steel Research, 55, 69-89

[3] EC3, Design of steel structures, Part 1-8: Design of joints (EN 1993-1-8), Brusseles: European Committee for Standardization (CEN), 2005.

[4] Zajec, L. (2019) Proračun priključaka u čeličnim konstrukcijama primjenom metode komponenata, završni rad, Građevinski fakultet, Sveučilište u Rijeci

[5] Krolo, P., Grandić, D. i Bulić, M. (2016) The Guidelines for Modeling the Preloading Bolts in the Structural Connection Using Finite Element Method, Journal of Computational Engineering

[6] Shi, G., Shi, Y., Wang, Y. i Bijlaard, F. (2010) Monotonic Loading Tests on SemiRigid End-Plate Connections with Welded I-Shaped Columns and Beams, Advances in Structural Engineering, vol. 13, no. 2, 215-229 